\title{
Community Nurse-led clinic: competence and accountability in the management of complex chronic cardiac care within the integrated Hospital-Territory network
}

Donatella Radini*, Michela Battiston, Salvatrice Cumbo, Franca Drigo, Gioia Sola, Nadia Zeriali, Sonia Zanetti, Alessandra Torricella, Endria Casanova Borca, Tiberio Pontoni, Giulia Barbati, Eliana Grande, Franco Humar, Kira Stellato, Andrea Di Lenarda

Cardiovascular Center - Health Authority $n^{\circ} 1$ and University of Trieste, Trieste, Italy

With the progressive aging of the population, the widespread increase in chronic and degenerative diseases and the need for constant improvement in the quality of services, outpatient nursing represents a new model of community organization and management of nursing care which can respond with competence to the diverse needs of the community.

Nurse-led Clinic takes care of patients with chronic heart disease (486 pts), heart failure (260 pts) and advanced heart failure (173 pts), outpatient and home management of patients with end-stage heart failure (continuous infusion of positive inotropic with portable insulin pumps, 14 pts), management of patients on oral anticoagulant therapy and new oral anticoagulants (398 pts). Across the clinics, the triage nurse takes care of patients who access the clinic through direct access or dedicated phone line for urgent assessment/monitoring of health needs. Out of $46.1 \%$ of patients who had a cardiovascular event and/or an active problem, only $1.3 \%$ was kept under observation in the ER or hospitalized. These patients had a greater hemodynamic instability that met criteria for activation of hospitalization (severe hypotension, desaturation, brady/ tachyarrhythmias, symptoms and signs of acute heart failure). The rest of the patients, with a minor instability were referred to the clinic nur-

Received: $1^{\text {st }}$ May 2014

*Address for correspondence: Cardiovascular Center, Health Authorithy $\mathrm{n}^{\circ} 1$ and University of Trieste, Trieste, Italy

E-mail: donatella.radini@ass1.sanita.fvg.it sing program with telephone and/or clinical follow-ups. This allows the activation of specific interventions needed to prevent hospitalization. Where necessary, local services (either district/home and/or social) are activated in order to respond to the needs expressed by the patient and his/her family.

Role of Nurses: Nursing interventions are initially done in conjunction with physician's visits to provide education and counseling for patients and caregivers to improve outcomes (mortality, readmissions to hospital, hospital length of stay). Patients and/or caregivers deemed requiring specific assessment and/or support are referred to a psychologist who also provides specific training and counseling supervision allowing for a steady update and strengthening of nurses' communication and educational skills. Follow-ups vary in frequency (e.g. monthly or bi-monthly) while medical followups still tend to be scheduled quarterly to yearly according to the clinical severity of the patient. The patient's letter contains both medical and nurses' information integrating the both assessments.

Conclusions: The Nurse-led Clinic may allow the improvement of health services and is a key tool for integrating hospital and community care within a health/social care framework of services which accompany the complexity of chronic care from the onset of the disease through supportive and palliative care assistance.

KEYWORDS: nurse-led clinic, community health, heart failure

CITATION: Cardiol Croat. 2014;9(5-6):236.

\section{Literature}

1. Richardson A, Cunliffe L. New horizons: the motives, diversity and future of 'nurse led' care. J Nurs Manag. 2003;11:80-4.

2. Schadewaldt V, Schultz TNurse-led clinics as an effective service for cardiac patients: results from a systematic review. Int J Evid Based Healthc. $2011 ; 9$ : 199-214.

3. Strömberg A, Martensson J, Fridlund B, Levin LA, Karlsson JE, Dahlström U. Nurse-led heart failure clinics improve survival and self-care behaviour in patients with heart failure: results from a prospective, randomised trial. Eur Heart J. 2003;24:1014-23.

4. Strömberg A, Martensson J, Fridlund B, Dahlström U. Nurse-led heart failure clinics in Sweden. Eur J Heart Fail. 2001;3:139-44. 